\title{
REPLACED RIGHT HEPATIC ARTERY ARISING FROM ABDOMINAL AORTA: A CASE REPORT
}

\author{
Gregory TSOUCALAS ${ }^{1}$, Eleni PANAGOULI ${ }^{1}$, Anastasios VASILOPOULOS ${ }^{1 凶,}$ \\ Anastasios KARAYIANNAKIS ${ }^{2}$, Vasilios THOMAIDIS ${ }^{1}$, Aliki FISKA ${ }^{1}$
}

${ }^{1}$ Department of Anatomy, Medical School, Democritus University of Thrace, Alexandroupolis, Greece

${ }^{2}$ Surgery Department, Medical School, Democritus University of Thrace, Alexandroupolis, Greece

Received 03 May 2021, Accepted 30 May 2021

https://doi.org/10.31688/ABMU.2021.56.2.18

\begin{abstract}
Introduction. Common hepatic artery is one of the three branches of Haller tripod and gives rise to the left and right hepatic arteries. We describe the case of a 62-year-old woman with the right hepatic artery rising from abdominal aorta, diagnosed incidentally during an abdominal computed tomography angiography.

Case report. The common hepatic artery was absent. In its place, the left hepatic artery originated from the celiac trunk, while the right replaced hepatic artery was observed arising directly from the abdominal aorta.

Conclusions. The uncommon abnormal vascular pattern presented has not been yet classified as an anatomic variation. Such arterial aberrations should be considered by surgeons during cholecystectomy, liver transplantation and pancreatectomy, to avoid complications.
\end{abstract}

Keywords: arterial branching variations, aberrant hepatic arteries, common hepatic artery, liver transplantation, abdominal surgery.

\section{List of abbreviations}

CHA - common hepatic artery RRHA - replaced right hepatic artery

CTA - computed tomography angiography

\section{Résumé}

Artère hépatique droite découlant de l'aorte abdominale: rapport de cas

Introduction. Lartère hépatique commune est l'une des trois branches du trépied de Haller et donne naissance aux artères hépatiques gauche et droite. Nous décrivons le cas d'une femme de 62 ans avec l'artère hépatique droite s'élevant de l'aorte abdominale, diagnostiquée fortuitement lors d'une angiographie tomodensitométrique abdominale.

Rapport de cas. L'artère hépatique commune était absente. À sa place, l'artère hépatique gauche provenait du tronc coliaque, tandis que l'artère hépatique remplacée droite a été observée provenant directement de l'aorte abdominale.

Conclusions. Le schéma vasculaire anormal rare présenté n'a pas encore été classé comme une variation anatomique. De telles aberrations artérielles doivent être prises en compte par les chirurgiens lors d'une cholécystectomie, d'une transplantation hépatique et d'une pancréatectomie, afin d'éviter les complications.

Mots-clés: variations de ramification artérielle, artères hépatiques aberrantes, artère hépatique commune, transplantation hépatique, chirurgie abdominale. 


\section{INTRODUCTION}

Common hepatic artery (CHA) is one of the three branches of Haller tripod, the other two being the splenic and left gastric arteries. CHA travels to the liver, after giving rise to the gastroduodenal and right gastric arteries, continuing then as proper hepatic artery. At the level of the porta hepatis, the artery divides into left and right branches, the latter providing a cystic branch for the gallbladder. These two branches enter the parenchyma of the liver and supply the left and right hepatic lobe, respectively ${ }^{1}$.

Deviations of the normal arterial branching pattern of the CHA are not rare, having an incidence of $41 \%{ }^{2}$. The most common among $\mathrm{CHA}$ variations are the so-called aberrant hepatic arteries. They are divided into two types, the accessory hepatic artery and the replaced hepatic artery $y^{3.5}$. The accessory hepatic artery is an additional vessel supplying a hepatic lobe, while the replaced hepatic artery provides the sole supply to a lobe, presenting an unexpected point of origin ${ }^{3,4}$. In some cases, the CHA may be absent, with an incidence of approximately $1.4 \%$ to $6.5 \%$ (average incidence $\approx 3.3 \%)^{2,6}$.

The existence of anatomical variations of the arterial pattern of the CHA and its branches may influence interventional procedures in surgery and radiology. Thus, a thorough knowledge concerning $\mathrm{CHA}$ branching variations is of great importance.

We describe a rare case of CHA absence, combined with a replaced right hepatic artery (RRHA) arising directly from the abdominal aorta.

\section{Case report}

A diagnostic abdominal computed tomography angiography (CTA) was performed in a 62-year-old female patient of Caucasian origin, who was investigated for a colo-rectal cancer. The imaging examination revealed that the celiac trunk had an unusual, trifurcated branching pattern. The left hepatic artery originated from the celiac trunk instead of the CHA, along with the left gastric and splenic arteries. An unexpected artery was observed, arising directly from the abdominal aorta, just below the origin of the celiac trunk (Fig. 1). The artery in question coursed to the liver, entering the right hepatic lobe, functioning therefore as a RRHA (Fig. 2). The left hepatic artery supplied the left hepatic lobe, as it was expected, with no further variations, substituting $\mathrm{CHA}$ in giving rise to the gastroduodenal, right gastric and cystic arteries. Superior and inferior mesenteric arteries followed the usual origin and branching pattern. Splenic and left gastric artery presented no variations, as well.

\section{Discussion}

According to the literature, CHA presents the classical anatomical pattern in $55-75 \%$ of the cases ${ }^{5}$. Many cases of aberrant hepatic arteries have been reported, while variations in the origin of the CHA arising from the Haller tripod have been observed, too? The absence of the CHA is also a possible vessel deviation. This pattern leads in most instances to the appearance of a replaced hepatic artery, which

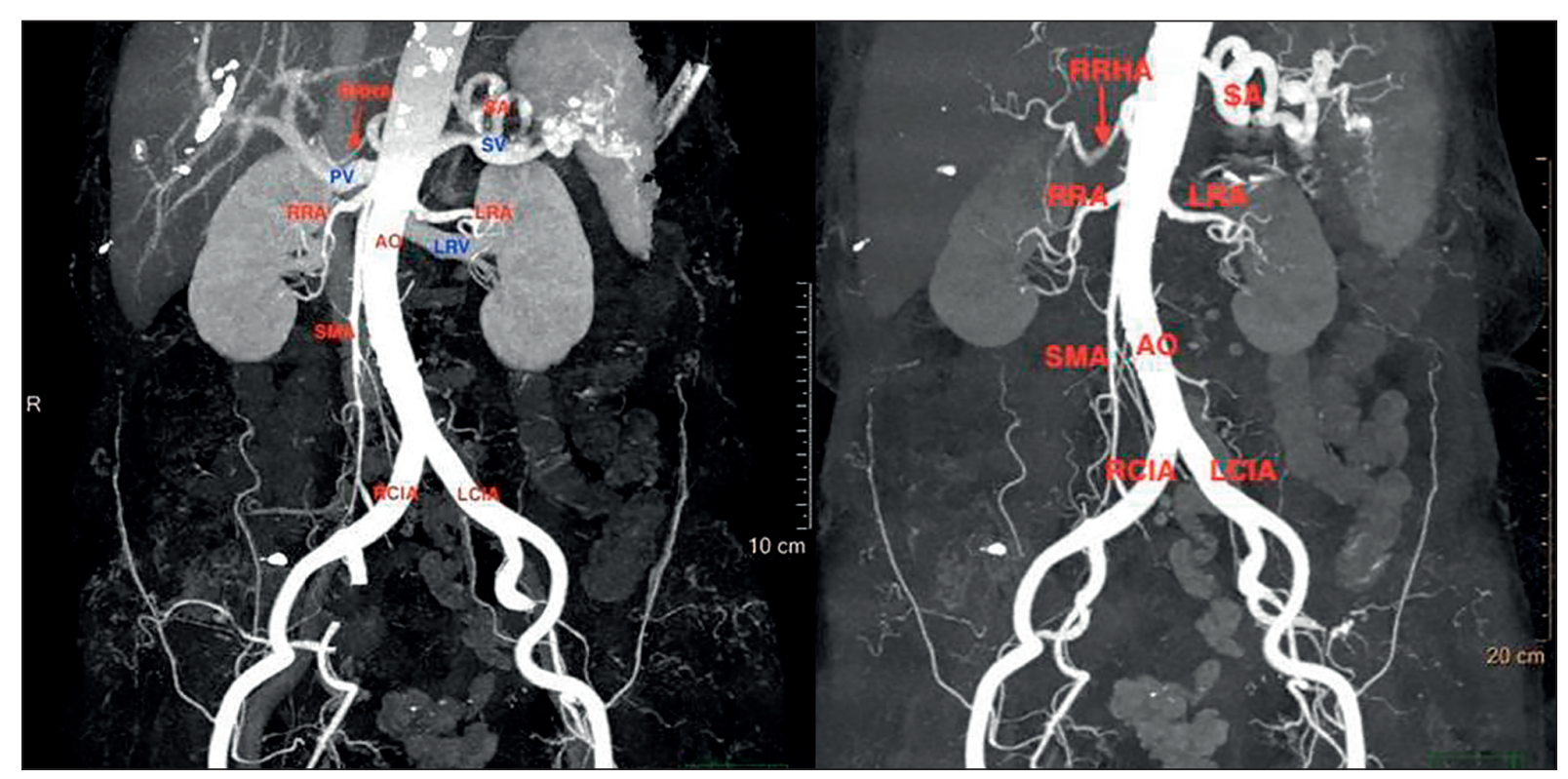

Figure 1. Origin of the replaced right hepatic artery directly from the abdominal aorta, just below the celiac trunk, 3D reconstructed images in arterial and early venous portal phase.

AO: Aorta, RRHA: replaced right hepatic artery, SA: splenic artery, SMA: superior mesenteric artery, RRA: right renal artery, LRA: left renal artery, LRV: left renal vein, PV: portal vein, SV: splenic vein, RCIA: right common iliac artery, LCIA: left common iliac artery. 
provides liver its arterial supply ${ }^{2}$. This study records such a case, where a RRHA is observed, while CHA is absent.

Several classifications of the anatomical variations of the CHA have been proposed in the literature. Michels, in 1966, proposed a classification based on autopsy series of 200 dissections (Table 1), a study in which the normal pattern was noted only in $55 \%$ of the cases ${ }^{8}$. In this classification, the terms "replaced" and "accessory" hepatic artery were firstly introduced. According to Michels classification, our case corresponds to type $4(1 \%)^{2,8}$. Hiat et al., in 1994,

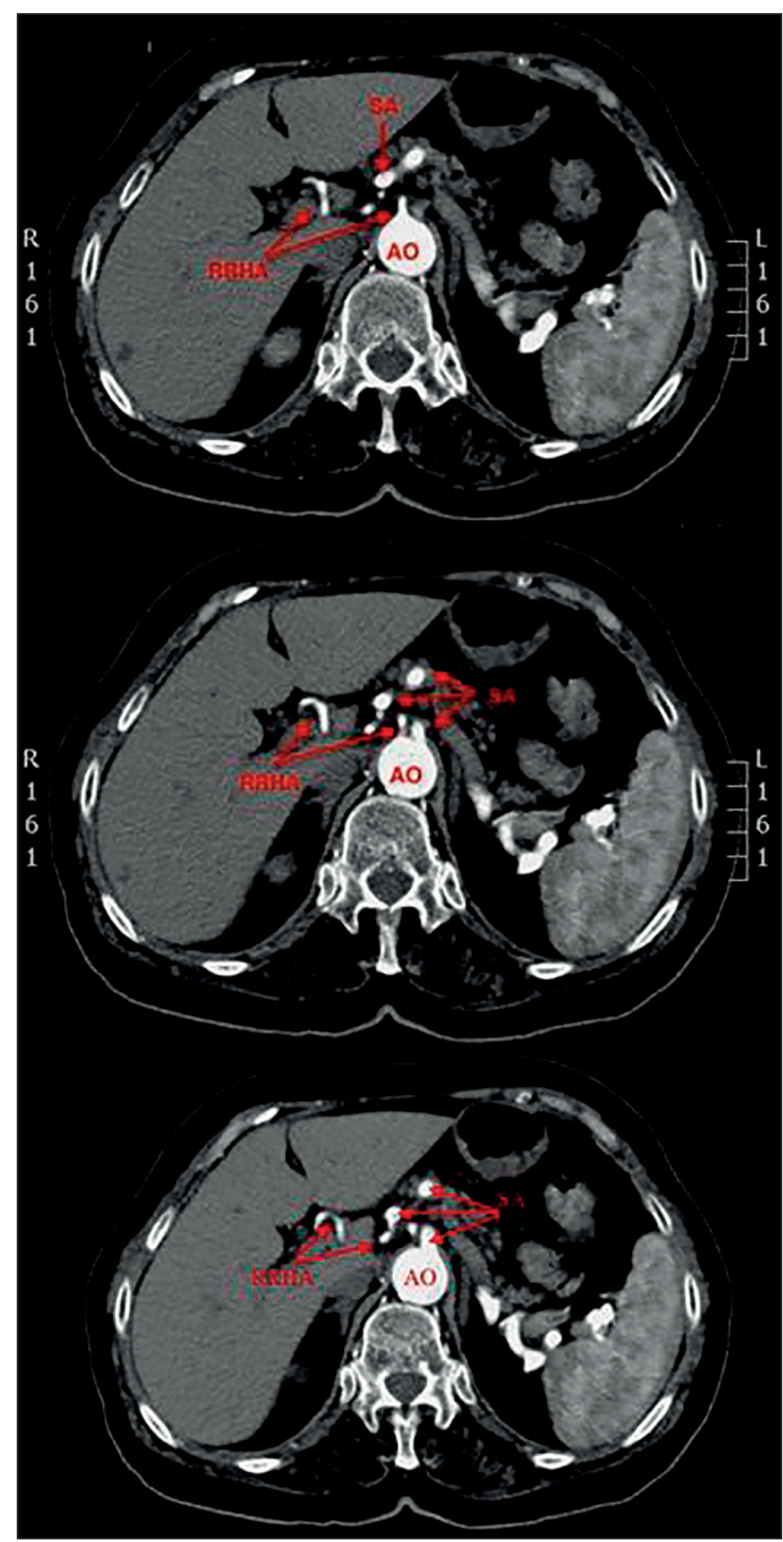

Figure 2. Axial images of contrast enchanced CT (arterial phase) depicting the replaced

right hepatic artery originating from the abdominal aorta and its course until it reaches the liver.

AO: Aorta, RRHA: replaced right hepatic artery, SA: splenic artery.
Table 1. Classifications

of variable anatomy patterns of $\mathrm{CHA}$

\begin{tabular}{cc}
\hline \multicolumn{2}{c}{ Michels classification $^{8}(\mathrm{n}=200)$} \\
\hline Type & Incidence \\
\hline 1. Normal & $55 \%(110 / 200)$ \\
\hline 2. RLHA from LGA & $10 \%(20 / 200)$ \\
\hline 3. RRHA from SMA & $11 \%(22 / 200)$ \\
\hline 4. RRHA and LHA & $1 \%(2 / 200)$ \\
\hline 5. ALHA & $8 \%(16 / 200)$ \\
\hline 6. ARHA & $7 \%(14 / 200)$ \\
\hline 7. ARHA and LHA & $1 \%(2 / 200)$ \\
\hline
\end{tabular}

8. RRHA and ALHA or RLHA and ARHA

$2 \%(4 / 200)$

\begin{tabular}{rr}
\hline 9. CHA from SMA & $2.5 \%(5 / 200)$ \\
\hline 10. CHA from LGA & $0.5 \%(1 / 200)$ \\
\hline
\end{tabular}

Hiat et al. classification ${ }^{7}(\mathrm{n}=1000)$

\begin{tabular}{|c|c|}
\hline Type & Incidence \\
\hline 1. Normal & $\begin{array}{c}75.7 \% \\
(757 / 1000) \\
\end{array}$ \\
\hline 2. RLHA or ALHA & $\begin{array}{c}9.7 \% \\
(97 / 1000) \\
\end{array}$ \\
\hline 3. RRHA or ARHA & $\begin{array}{c}10.6 \% \\
(106 / 1000)\end{array}$ \\
\hline 4. RLHA or ALHA and RRHA or ARHA & $\begin{array}{c}2.3 \% \\
(23 / 1000) \\
\end{array}$ \\
\hline 5. CHA from SMA & $\begin{array}{c}1.5 \% \\
(15 / 1000)\end{array}$ \\
\hline 6. CHA from abdominal aorta & $0.2 \%(2 / 1000)$ \\
\hline \multicolumn{2}{|c|}{ Huang et al. classification $^{6}(n=2170)$} \\
\hline Type & Incidence \\
\hline 1. RCHA arising from the SMA & $\begin{array}{c}1.29 \% \\
(28 / 2170) \\
* 0.7 \% \\
\end{array}$ \\
\hline $\begin{array}{l}\text { 2. RCHA arising from the SMA with a } \\
\text { circumambulated approach anterior to } \\
\text { the pancreatic head }\end{array}$ & $\begin{array}{c}0.05 \% \\
(1 / 2170) \\
* 0.003 \% \\
\end{array}$ \\
\hline $\begin{array}{l}\text { 3. } \mathrm{RCHA} \text { arising from the abdominal } \\
\text { aorta }\end{array}$ & $\begin{array}{c}0.05 \% \\
(1 / 2170) \\
* 0.5 \%\end{array}$ \\
\hline $\begin{array}{l}\text { 4. RLHA arising from the LGA and } \\
\text { RRHA arising from the SMA }\end{array}$ & $\begin{array}{c}0.23 \% \\
(5 / 2170) \\
{ }^{*} 0.62 \% \\
\end{array}$ \\
\hline $\begin{array}{l}\text { 5. RLHA arising from the LGA and } \\
\text { RRHA arising from the CT }\end{array}$ & $\begin{array}{c}0.09 \% \\
(2 / 2170) \\
* 0.01 \% \\
\end{array}$ \\
\hline $\begin{array}{l}\text { 6. RLHA arising from the aberrant GDA } \\
\text { and RRHA arising from the SMA }\end{array}$ & $\begin{array}{c}0.05 \% \\
(1 / 2170) \\
* 0.01 \%\end{array}$ \\
\hline
\end{tabular}

*Incidences pooled from the meta-analysis of Cirocchi et al. $^{2}$

Abbreviations: CHA: common hepatic artery, SMA: superior mesenteric artery, CT: celiac trunk, RCHA: replaced common hepatic artery, GDA: gastroduodenal artery, LGA: left gastric artery, RRHA: replaced right hepatic artery, RLHA: replaced left hepatic artery. 
Table 2. Sites of origin of RRHA.

\begin{tabular}{cc}
\hline \multicolumn{2}{c}{ Replaced Right Hepatic Artery (RRHA) } \\
\hline Site of origin & Incidence \\
\hline SMA & $8.3-21 \%$ \\
\hline CT & $1.33-6.7 \%$ \\
\hline GDA & $2.33-6.0 \%$ \\
\hline Abdominal aorta & $0.33-1.7 \%$ \\
\hline
\end{tabular}

Abbreviations: SMA: superior mesenteric artery, CT: celiac trunk, GDA: gastroduodenal artery, LGA: left gastric artery, RRHA: replaced right hepatic artery.

after studying 1000 hepatic samples, proposed a modification of Michels' classification. Michels' ten types of variations were reduced into six, and aberrant arteries, both replaced and accessory, were summarized into three types (Table 1). As a result, Hiat et al. classification did not include a detailed description of the aberrant hepatic arteries?

Huang et al., in 2015, suggested adding one more class to the six-type classification, to include the absence of the CHA. These authors have described all the possible types of replaced hepatic arteries and their variable sites of origin in cases where the normal CHA is absent, based on observations made on a group of 2170 patients (Table 1$)^{6}$. The absence of CHA was recorded in $1.8 \%$ of the studied cases, while no other variations of the CHA were mentioned $^{6,7}$. Thus, Huang et al. did not include a RRHA pattern of origin directly from the abdominal aorta? A meta-analysis performed by Cirocchi et al in 2018 presented more complete and detailed occurrences of the classification types, reviewing 54 studies, including a total of 26250 patients $^{2}$. According to this meta-analysis, the overall frequency of $\mathrm{CHA}$ absence was estimated to be $3.3 \%(876 / 26250)^{2}$, resulting in the modification of all corresponding incidences of hepatic arterial branching variations (Table 1).

The most common sites of origin for an aberrant hepatic artery have been recorded to be the superior mesenteric artery and the left gastric artery, a finding occurring in both Hyat and Michels' classifications? Other rarer locations of origin can be the gastroduodenal artery, the celiac artery or the abdominal aorta $^{3,6}$. More specifically, an aberrant (accessory or replaced) right hepatic artery is reported to emerge more commonly from the superior mesenteric artery (Table 2), while a left one had been noted to branch off the left gastric artery ${ }^{3,5,7}$. The RRHA is also reported to originate from the celiac trunk, the gastroduodenal artery and the abdominal aorta (Table 2). The emergence of the RRHA directly from the abdominal aorta, as in the case presented, is considered to be a rather rare branching pattern, with an incidence ranging between $0.33 \%$ and $1.7 \%$.
During liver transplantation procedures, a complete dissection of common and replaced hepatic arteries takes place. Thus, identification and proper preservation of such vessels is of great importance for the outcome of the surgical intervention. If arterial branching variations are detected, surgeons may have to reconstruct the liver supplying arteries of the donor before the transplantation ${ }^{3}$. Specialized centers report that anatomic variations of the hepatic artery in liver grafts is a common finding and will lead to an increase of the incidence of an early hepatic artery thrombosis 9 . Furthermore, in cases of branching variations, biliary complications, biliary leaks and/or biliary stricture, may appear ${ }^{10}$.

Interventional radiology may encounter difficulties in dealing with aneurysms of aberrant arteries, especially when embolism is necessary ${ }^{11}$. Vascular injury may occur during pancreatoduodenectomy, cholecystectomy and pancreatectomy. The evaluation of the local anatomical details should precede abdominal surgeries ${ }^{12}$. Every surgeon or interventional physician should always consider the possible existence of aberrant hepatic arteries. Nevertheless, replaced hepatic arteries seem to be more clinically significant, since they provide the sole supply to the corresponding hepatic lobe in cases of CHA absence 5 .

\section{Conclusions}

We presented a case of CHA absence, combined with a RRHA originating directly from the abdominal aorta. This rare abnormal pattern has not been yet classified as an anatomic variation, according to the Classification System for CHA absence. Such arterial aberrations may lead to complications during upper abdominal surgical interventions.

\section{Author Contributions:}

G.T., V.T. and A.F. were responsible for the conception and design of the manuscript. A.K. was responsible for the diagnostic procedures, clinical diagnosis, and treatment decisions. E.P. performed the statistical analysis. A.V. and G.T. wrote the manuscript. A.F. and V.T. revised and approved the manuscript. All authors have read and agreed to the published version of the manuscript.

\section{Compliance with Ethics Requirements:}

"The authors declare no conflict of interest regarding this article"

"The authors declare that all the procedures and experiments of this study respect the ethical standards in the Helsinki Declaration of 1975, as revised in 2008(5), as well as the national law. Informed consent was obtained from the patient included in the study"

"No funding for this study" 


\section{Acknowledgements:}

\section{None}

\section{References}

1. Standring S, Borley NR, Collins P, et al (eds.). Gray's anatomy. The anatomical basis of clinical practice. 40th ed. Edinburgh: Elsevier, 2008.

2. Cirocchi R, D'Andrea V, Lauro A, et al. The absence of the common hepatic artery and its implications for surgical practice: Results of a systematic review and meta-analysis. Surgeon 2019;17(3): 172-185.

3. Panagouli E, Venieratos D. Right accessory hepatic artery arising from the left gastric artery: a case report. Romanian Journal of Morphology and Embryology 2011;52(suppl 3):1143-1145.

4. Asif M, Anewenah LS, Reddy N, Khan FA. Replaced right and left hepatic arteries: a variation in origin and course. BMJ Case Reports 2017;2017: bcr2016218345.

5. Dandekar U, Dandekar K, Chavan S. Right hepatic artery: a cadaver investigation and its clinical significance. Anatomy Research International 2015;2015: 412595.

6. Huang CM, Chen RF, Chen QY, et al. Application value of a 6-type classification system for common hepatic artery absence during laparoscopic radical resections for gastric cancer: a large-scale single-center study. Medicine (Baltimore) 2015;94(32): e1280.

7. Hiatt JR, Gabbay J, Busuttil RW. Surgical anatomy of the hepatic arteries in 1000 cases. Annals of Surgery 1994;220(1): 50-52.

8. Michels NA. Newer anatomy of the liver and its variant blood supply and collateral circulation. The American Journal of Surgery 1966;112(3): 337-347.

9. Fouzas I, Papanikolaou C, Katsanos G, et al. Hepatic artery anatomic variations and reconstruction in liver grafts procured in Greece: the effect on hepatic artery thrombosis. Transplantation Proceedings 2019;51(2): 416-420.

10. Koc O, Yaylak F, Sarici B, Soyer V, Yilmaz S. Clinical outcomes of donor hepatic artery to recipient replaced right hepatic artery anastomosis in living-donor liver transplantation. Transplantation Proceedings 2015;47(5): 1478-1481.

11. Bains L, Kori R, Sharma R, Kaur D. Replaced right hepatic artery pseudoaneurysm managed with coil embolisation. BMJ Case Reports 2019;12(9):e227921.

12. Staśkiewicz G, Torres K, Denisow M, Torres A, CzekajskaChehab E, Drop A. Clinically relevant anatomical parameters of the replaced right hepatic artery (RRHA). Surgical and Radiologic Anatomy 2015;37(10): 1225-1231. 